\title{
Primary plasmacytoma of the thyroid
}

\author{
S. Cheslyn-Curtis ${ }^{1 *}$ and A.B. Akosa ${ }^{2 \dagger}$
}

Departments of ${ }^{1}$ Surgery and ${ }^{2}$ Histopathology, Wexham Park Hospital, Slough, Berkshire SL2 4HL, UK.

Summary: Primary plasmacytoma of the thyroid is a very rare tumour. We report a case and emphasize the importance of excluding multiple myeloma which may present as an extramedullary plasmacytoma. Histological diagnosis has been simplified by the use of immunohistochemical techniques.

\section{Introduction}

Extra-medullary primary plasmacytomas are uncommon and their occurrence in the thyroid is rare. ${ }^{1,2}$ Only two cases have been reported from Britain. ${ }^{3}$ Histological diagnosis has been made much easier by the demonstration of a monotypic population of plasma cells, using immunohistochemical techniques. However, its presence as an early manifestation of multiple myeloma must be excluded. A primary plasmacytoma of the thyroid is described supported by immunohistochemical and ultrastructural examination. The presentation and management of these tumours is discussed.

\section{Case report}

A 78 year old woman presented with a 6-month history of a swelling in the left side of her neck. Her only symptom was mild dysphagia. Physical examination revealed a firm, smooth, non-tender, mobile enlargement of the left lobe of the thyroid with deviation of the trachea. Thyroid function, haemoglobin, serum proteins and electrolytes were normal. Chest X-ray showed marked tracheal displacement and an ultrasound scan confirmed the presence of a solid mass in the left lobe of the thyroid.

At operation, a well encapsulated tumour mass $(8 \mathrm{~cm} \times 4 \mathrm{~cm} \times 3 \mathrm{~cm})$ was found in association with enlarged lymph nodes lying both anterior to the gland and also within the left deep cervical chain. A left thyroid lobectomy with lymph node biopsy was performed.

Light microscopy showed thyroid and lymph node tissue diffusely infiltrated by sheets of mature

Correspondence: Miss S. Cheslyn-Curtis, M.S., F.R.C.S., Department of Gastroenterology, The Middlesex Hospital, London W1N 8AA, UK.

Present addresses: *The Middlesex/University College Hospitals, London, and †Hammersmith Hospital, London, UK.

Accepted: 29 January 1990 plasma cells (Figure 1). Immature and atypical forms of plasma cells were infrequent and mitoses rare. There were some residual thyroid follicles with marked lymphocytic infiltration suggestive of an underlying chronic thyroiditis.

Immunohistochemistry was performed using the unlabelled antibody (PAP) immunoperoxidase method with trypsinization for immunoglobulins (IgG, IgM and IgA) and for light chains (kappa and lambda). Plasma cells showed a striking intracytoplasmic staining for IgG and kappa light chains in both the thyroid and lymph node tissue. Staining for lambda light chains, IgM and IgA was negative. Electron microscopy confirmed the neoplastic features of the plasma cells, including well developed and stacked rough endoplasmic reticulum and numerous mitochondria. These are the features of a plasmacytoma.

Further investigations were performed to determine whether the tumour was solitary or a manifestation of multiple myeloma. The serum protein level was $82 \mathrm{~g} / \mathrm{l}$ with an albumin/globulin ratio of 1.1:1 and a normal immunoglobulin profile. Protein electrophoresis showed a broad atypical band

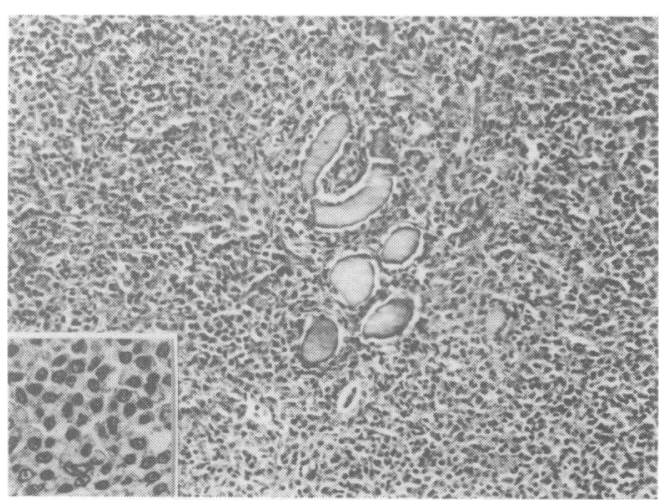

Figure 1 Sheets of mature plasma cells with residual thyroid follicles containing colloid. Low power $\times 80$. 
in the gamma region which was identified by immunoelectrophoresis as IgG kappa. Protein electrophoresis and immunoelectrophoresis reverted to normal within 4 months of the operation. Bone marrow, skeletal survey and isotope bone scan were normal and Bence Jones protein negative.

Treatment was completed by local irradiation with $4000 \mathrm{cGy}$ to the thyroid region and adjacent lymph nodes. The patient is well 18 months later with no evidence of local or distant recurrence.

\section{Discussion}

Extra-medullary plasmacytoma occurs either as a manifestation of multiple myeloma or as a solitary primary tumour. Oberkircher et al. ${ }^{4}$ found that $17 \%$ ( 24 of 141 ) of patients with multiple myeloma presented with extra-medullary tumours but the incidence of thyroid involvement has been reported to be only $2.6 \%$ ( 7 of 272 ) among extra-medullary plasmacytomas. ${ }^{5}$ Primary plasmacytoma of the thyroid is very rare. Hazard and Schildecker ${ }^{1}$ found two cases following 14,000 thyroid operations performed over a 22-year period and MacPherson et $a .^{2}$ discovered one among 870 thyroid tumours. A review of the 28 cases of primary plasmacytoma of the thyroid which have been reported has shown that most patients present in the fifth to seventh decades and that there is no sex difference.

The diagnosis of primary plasmacytoma can be made only after the exclusion of multiple myeloma. Investigations should include pre- and postoperative serum electrophoresis, bone marrow examination and a skeletal survey or bone scan. Preoperative serum electrophoresis demonstrated an M-protein in 11 cases which by immunoelectrophoresis has shown four, including our own, with IgG kappa chains. ${ }^{2,4,6}$ In all cases, serum proteins reverted to normal within 2 to 9 months of removal of the tumour. Three of these patients had Bence

\section{References}

1. Hazard, J.B. \& Schildecker, W.W. Plasmacytoma of the thyroid. Am J Pathol 1949, 25: 819-820.

2. MacPherson, T.A., Dekker, A. \& Kapadia, S.B. Thyroid gland plasma cell neoplasm (plasmacytoma). Arch Pathol Lab Med 1981, 105: 570-572.

3. More, J.R., Dawson, D.W., Ralston, A.J. \& Craig, I. Plasmacytoma of the thyroid. J Clin Pathol 1968, 21: $661-667$.

4. Oberkircher, P.E., Miller, W.T. \& Arger, P.H. Nonosseous presentation of plasma-cell myeloma. Radiology 1972, 104: 515-520.

5. Wiltshaw, E. The natural history of extramedullary plasmacytoma and its relation to solitary myeloma of bone and myelomatosis. Medicine 1976, 55: 217-238.

6. Papadimitriou, C.S. \& Schwarze, E.W. Extramedullary nongastrointestinal plasmacytoma. An immunohistochemical study of sixteen cases. Pathol Res Pract 1983, 176: 306-312.
Jones proteinuria which also reverted to normal after treatment. ${ }^{7-9}$ Bone marrow examination was normal in all cases.

The histological distinction of primary plasmacytoma from plasma cell granuloma is difficult. ${ }^{10}$ Tissue immunostaining for immunoglobulins, by the PAP technique, has simplified the diagnosis since the demonstration of a monotypic population of plasma cells establishes the neoplastic nature of the lesion and correspondence with the immunoelectrophoretic characterization of serum protein establishes the site of production. Our case demonstrated a striking intracytoplasmic staining of IgG and kappa light chains in both the thyroid and lymph node tissue and corresponded with the serum immunoelectrophoretic finding of a raised IgG kappa protein.

Primary plasmacytomas of the thyroid appear to have an excellent prognosis even when there is involvement of adjacent lymph nodes. Patients have been followed for a median of 3 years (range 1-23 years). There has been no mortality from recurrent disease and the two tumours that recurred responded well to further treatment with either radiotherapy or chemotherapy. ${ }^{1,11}$ Hemi- or total thyroidectomy with regional lymph node biopsy is the initial treatment of choice. Local irradiation is probably an advisable adjunct to surgery when the juxtathyroid lymph nodes are involved by tumour. Further surgical clearance of these lymph nodes may be considered, although radical block dissections of the neck seem to be unnecessary because of the excellent prognosis of the tumour despite lymph node involvement. The rarity of plasmacytoma of the thyroid makes it difficult to determine optimum management for these patients.

\section{Acknowledgements}

We would like to thank Mr S.E. Knight, Consultant Surgeon and Dr M.H. Ali, Consultant Histopathologist, for their permission to report this case.

7. Matsubayashi, S., Tamai, H., Suzuki, T. et al. Extramedullary plasmacytoma of the thyroid gland producing gamma heavy chain. Endocrinol Jpn 1985, 32: 427-433.

8. Chen, K.T., Bauer, V. \& Bauer, F. Localized thyroid plasmacytoma. J Surg Oncol 1986, 32: 220-222.

9. Otto, S., Peter, I., Vegh, S., Juhos, E. \& Besznyak, I. Gamma-chain heavy-chain disease with primary thyroid plasmacytoma. Arch Pathol Lab Med 1986, 110: 893-896.

10. Holck, S. Plasma cell granuloma of the thyroid. Cancer 1981, 48: 830-832.

11. Corwin, J. \& Lindberg, R.D. Solitary plasmacytoma of bone $v s$ extramedullary plasmacytoma and their relationship to multiple myeloma. Cancer 1979, 43: 1007-1013. 